\title{
Expression and clinical importance of a newly discovered alternative splice variant of the gene for acrosin binding protein found in human brain tumors
}

\author{
Baolong Zheng*๑
}

\begin{abstract}
Background: Acrosin binding protein $(A C R B P)$ is a member of the cancer-testis antigen (CTA) family. Normally, $A C R B P$ mRNA is expressed only in seminiferous tubules, while abnormally it is expressed in various types of cancers in tumor tissues, such as brain tumor.

Objectives: To determine the expression and clinical impact of a newly discovered splice variant of $A C R B P$ in brain tumor.

Methods: Total RNA was extracted and reverse transcribed from 92 tumor specimens and 3 cell lines. Primers were designed to determine the expression of the new splice variant in all the samples. Quantitative real-time PCR (qPCR) was conducted for samples positive in reverse transcriptase-PCR. Association of the expression of $A C R B P$ with the clinicopathological features of the various brain tumors was assessed statistically.

Results: The primers identified a newly discovered splice variant of $A C R B P$ named $A C R B P-V 5 a$. The proportions of samples of the various brain tumor types positive for the $A C R B P-V 5 a$ splicing variant were as follows: astrocytoma 10/33 (30\%), glioblastoma 10/30 (33\%), medulloblastoma 14/29 (48\%), all tumors 34/92 (37\%). Although we did not find a significant difference in the proportions of samples of various types of brain tumor tissues positive for the new splice variant $(P>0.05)$, levels of expression of the $A C R B P-V 5 a$ splice variant were significantly different for tumor grade $(P=0.01)$ and tumor type $(P=0.02)$.

Conclusions: A newly discovered splice variant, $A C R B P-V 5 a$, is present in brain tumor. The new splicing variant may have discriminative value and potential importance in molecular-targeted therapy for brain tumors.
\end{abstract}

Keywords: $A C R B P$ protein, human; alternative splicing; antigens, neoplasm; brain neoplasms; cancer-testis antigen, human

The gene encoding acrosin binding protein $(A C R B P)$ is also known as CT23; SP32 and OY-TES-1 is located on chromosome 12 p12-p13, and includes 10 exons [1]. ACRBP is a precursor and intermediate binding protein of serine protease, which is specifically located in the acrosome of germ cells and sperm $[2,3] . A C R B P$ was asserted as a Pem (placenta and embryos) expression gene and functions by binding to proacrosin to package and condense the acrosin zymogen in the

*Correspondence to: Baolong Zheng, Clinic for Neurosurgery, University Hospital Düsseldorf, Düsseldorf 40225, Germany,

e-mail: baolong.z@foxmail.com

Department of Neurosurgery, The First Affiliated Hospital of Guangxi Medical University, Nanning, Guangxi 530021, China

¿ Open Access. ๑ 2020 Zheng, published by Sciendo. (c) BY-NC-ND This work is licensed under the Creative Commons Attribution NonCommercial-NoDerivatives 4.0 License. 
acrosomal matrix [4]. As an additional member of the cancertestis antigen (CTA) family, it became known as a human homolog of the precursor of human myosin binding protein SP32 [3-5]. The expression profile of $A C R B P$ shows that the protein has the characteristics of a CTA and causes a strong immune response in some cancer patients [1]. For example, the mRNA of $A C R B P$ is highly expressed in gliomas and polyclonal antibody for the $A C R B P$ antigen was found in the serum of 5/36 (14\%) of patients with glioma, but absent in all the serum samples from 107 healthy donors [6]. ACRBP is rarely expressed in normal adult tissues (except, of course, in testis tissue) [1].

Alternative splicing offers the largest potential for molecular diversity and controlled regulation in the cell [7]. Alternative splicing events may occur in up to $50 \%$ of human genes, leading to the enormous variety of potential coding regions of the genome [8]. Splicing events can lead to faults and can cause various diseases, including cancers [9]. Some alterations are relevant to tumor progression, metastasis, therapy resistance, and oncogenic processes [10].

A $55 \mathrm{kDa}$ porcine proacrosin precursor protein of $A C R B P$ is modified posttranslationally to produce a $32 \mathrm{kDa}$ mature form [2]. In mice, 2 different types of $A C R B P$ are identified: wild-type $A C R B P-W$ and variant $A C R B P-V 5$. Investigators have found that $A C R B P-W$ and $A C R B P-V 5$ presented and played a role in the process of acrosome formation in mice. At first, $A C R B P-V 5$ controls the formation and configuration of the acrosomal granule; subsequently, $A C R B P-W$ maintains the inactivation of proacrosin [11].

To our knowledge, alternative splicing in human $A C R B P$ has not yet been reported. Therefore, our study sought to determine whether there was alternative splicing of $A C R B P$, thus $A C R B P-V 5 a$, in human brain tumors.

\section{Methods}

\section{Specimens and cells}

After the use of human tissue for this study was approved by the Ethics Committee of the First Affiliated Hospital of Guangxi Medical University (approval No. KY-E- 011, January 13, 2018) and after patients included in this study signed written informed consent forms, we obtained 92 surgical tissue specimens (33 primary astrocytomas, 30 glioblastomas, and 29 medulloblastomas) from the patients. All samples were preserved in liquid $\mathrm{N}_{2}$. This study was conducted in accordance with the ethical standards of the 1964 Declaration of Helsinki and its contemporary amendments. All patients underwent primary tumor resection and had no radiotherapy or chemotherapy before their surgery. Stable human cell lines of glioma (SHG-44) and liver cancers (hep G2 and SMMC7721) were cultured with Dulbecco's Modified Eagle's medium supplemented with $10 \%$ fetal bovine serum of premium quality (Wisent, Canada).

\section{cDNA primer design}

The sequences of splicing variants of $A C R B P$ (NCBI Gene ID: 84519 ) were predicted by using alternative splicing sequence databases from Homo sapiens, sourced from NCBI Genome (http://www.ncbi.nlm.nih.gov/genome/), the Ensembl Alternative Database (http://asia.ensembl.org/), and TCGA SpliceSeq Database (http://projects.insilico. us.com/TCGASpliceSeq/index.jsp). Primers for ACRBP-V5a (ENST00000536350.5) were designed using Primer Premier (version 5.0, Premier Biosoft) and aligned using BLAST (https://blast.ncbi.nlm.nih.gov/Blast/). Forward primer 5'-TGAAGTCTCACCCACCACGATG-3' and reverse primer 5'-GCTAGGAAAATGGGCTTCTCA-3' were designed to amplify a 600-bp segment of $A C R B P-V 5 a$, between exons 4 and 5a (Figure 1), and synthesized by Sangon Biotech Co. (Shanghai, China).

\section{RNA and CDNA preparation}

All samples were handled in a frozen state. Total RNA was extracted using a FastPure Cell/Tissue Total RNA Isolation Mini Kit (Vazyme Biotech Co., Nanjing, China). cDNA was prepared by reverse transcription of $1 \mu \mathrm{g}$ total RNA (HiScript II 1st Strand cDNA Synthesis Kit; Vazyme Biotech Co.), following the instruction manual from the manufacturer. RNA integrity was confirmed spectrophotometrically (Tiangen Biotech Co., China). All experimental materials and reagents were RNA-free.

\section{RT-PCR}

Reverse-transcribed cDNA was amplified with the designed primers using a RT-PCR reverse transcription kit (Eppendorf) using the following cycling parameters: $1 \mathrm{~min}$ at $94{ }^{\circ} \mathrm{C}$; $1 \mathrm{~min}$ at $59{ }^{\circ} \mathrm{C} ; 2 \mathrm{~min}$ at $72{ }^{\circ} \mathrm{C}$ for 35 cycles; and a final extension at $72{ }^{\circ} \mathrm{C}$ for $8 \mathrm{~min}$ [12]. A positive-control experiment was performed using the same primers for the human liver cancer cell line, SMMC7721 (Figure 2). The cell line fragment was subcloned and sequenced by Sangon Biotech Co. (China) to confirm its identity (Figure 3). Another experiment was performed to identify the quality of cDNA with 
1 CGGGACGCGGGCGGATCTTCTCCCGCCATCAGGAAGCCAGCCGCTCGCTTCCTTCCCTCA $\ldots \ldots \ldots \ldots \ldots \ldots \ldots \ldots \ldots \ldots \ldots$-M-R--K--P--A--A--G--F--L--P--S-

61 CTCCTGAAGGTCCTGCTCCTGCCTCTGGCACCTGCCGCAGCCCAGGATTCGACTCAGGCC 12 -L--L--K--V--L--L--L--P--L--A--P--A--A--A--Q--D--S--T--Q--A-

121 TCCACTCCAGGCAGCCCTCTCTCTCCTACCGAATACGAACGCTTCTTCGCACTGCTGACT 32 -S--T--P--G--S--P--L--S--P--T--E--Y--E--R--F--F--A--L--L--T-

181 CCAACCTGGAAGGCAGAGACTACCTGCCGTCTCCGTGCAACCCACGGCTGCCGGAATCCC 52 -P--T--W--K--A--E--T--T--C--R--L--R--A--T--H--G--C--R--N--P-

241 ACACTCGTCCACCTGGACCAATATGAAAACCACGGCTTAGTGCCCGATGGTGCTGTCTGC 72 -T--L--V--Q--L--D--Q--Y--E--N--H--G--L--V--P--D--G--A--V--C-

301 TCCAACCTCCCTTATCCCTCCTGCTTTCACTCTTTCTCCCACTTCACTCACTACCGTTCC $92-\mathrm{S}--\mathrm{N}--\mathrm{L}--\mathrm{P}--\mathrm{Y}--\mathrm{A}--\mathrm{S}--\mathrm{W}--\mathrm{F}--\mathrm{E}--\mathrm{S}--\mathrm{F}--\mathrm{C}--\mathrm{Q}--\mathrm{F}--\mathrm{T}--\mathrm{H}--\mathrm{Y}--\mathrm{R}--\mathrm{C}-$

361 TCCAACCACGTCTACTATCCCAAGAGAGTCCTGTGTTCCCAGCCAGTCTCTATTCTCTCA 112 -S--N--H--V--Y--Y--A--K--R--V--L--C--S--Q--P--V--S--I--L--S-

421 CCTAACACTCTCAAGGAGATAGAAGCTTCAGCTGAAGTCTCACCCACCACGATGACCTCC 132 -P--N--T--L--K--E--I--E--A--S--A--E--V--S--P--T--T--M--T--S-

481 CCCATCTCACCCCACTTCACAGTCACAGAACGCCAGACCTTCCACCCCTGCCCTGAGAGG 152 -P--I--S--P--H--F--T--V--T--E--R--Q--T--F--Q--P--W--P--E--R-

541 CTCAGCAACAACGTGGAAGAGCTCCTACAATCCTCCTTGTCCCTGGGAGGCCAGGAGCAA 172 -L--S--N--N--V--E--E--L--L--Q--S--S--L--S--L--G--G--Q--E--Q-

601 GCGCCACAGCACAACCAGCAGCAAGGAGTCGAGCACAGCCAGGACCCCACACAAGAACAC 192 -A--P--E--H--K--Q--E--Q--G--V--E--H--R--Q--E--P--T--Q--E--H-

661 AAGCAGGAAGAGGGGCAGAAACAGGAAGAGCAAGAAGAGGAACAGGAAGAGGAGGGAAAG $212-\mathrm{K}--\mathrm{Q}--\mathrm{E}--\mathrm{E}--\mathrm{G}--\mathrm{Q}--\mathrm{K}--\mathrm{Q}--\mathrm{E}--\mathrm{E}--\mathrm{Q}--\mathrm{E}--\mathrm{E}--\mathrm{E}--\mathrm{Q}--\mathrm{E}--\mathrm{E}--\mathrm{E}--\mathrm{G}--\mathrm{K}-$

721 CAGGAAGAAGGACAGGGGACTAAGGAGGGACGGGAGGCTGTGTCTCAGCTGCAGACAGAC 232 -Q--E--E--G--Q--G--T--K--E--G--R--E--A--V--S--Q--L--Q--T--D-

781 TCAGAGCCCAAGTTTCACTCTGAATCTCTATCTTCTAACCCTTCCTCTTTTGCTCCCCGG 252 -S--E--P--K--F--H--S--E--S--L--S--S--N--P--S--S--F--A--P--R-

841 GTACGAGAAGTAGAGTCTACTCCTATGATAATGGAGAACATCCAGGAGCTCATTCGATCA 272 -V--R--E--V--E--S--T--P--M--I--M--E--N--I--Q--E--L--I--R--S-

901 GCCCAGCAAATACATCAAATGAATGAAATATATCATGACAACTCCTACTGCAGAAACCAA $292-\mathrm{A}--\mathrm{Q}--\mathrm{E}--\mathrm{I}--\mathrm{D}--\mathrm{E}--\mathrm{M}--\mathrm{N}--\mathrm{E}--\mathrm{I}--\mathrm{Y}--\mathrm{D}--\mathrm{E}--\mathrm{N}--\mathrm{S}--\mathrm{Y}--\mathrm{W}--\mathrm{R}--\mathrm{N}--\mathrm{Q}-$

961 AACCCTGGCAGGTATAGGAAGTTTTGACTCTGTCATCCACCСTGCССTCCСTTCTCCCTT

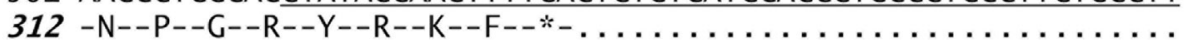

1021 TCTTGGGAGTGAGAAGCCCATTTTCCTAGCTTC
60

11

120

31

180

51

240

71

300

91

360

111

420

131

480

151

540

171

600

191

660

211

720

231

780

251

840

271

900

291

960

311

1020

319

1053

Figure 1. Nucleotide and predicted amino acid sequences for the variant of the gene for acrosomal binding protein, $A C R B P$-V5a. The nucleotide sequence is shown above the predicted amino acid sequence. Numbers on both sides correspond to nucleotides (roman) and amino acid residues (bold italic). The exon $5 \mathrm{a}$ is underlined. Two potential N-glycosylation sites are shaded (based on the NetNGlyc1.0 Server).

a pair of primers for the gene for human glyceraldehyde 3-phosphate dehydrogenase, GAPDH, 5'-CAAGGTCATCCATGACAACTTTG-3' and 5'-GTCCACCACCCTGTTGCTGTAG-3', using the following cycling parameters: $30 \mathrm{~s}$ at $94{ }^{\circ} \mathrm{C} ; 30 \mathrm{~s}$ at $55^{\circ} \mathrm{C} ; 1 \mathrm{~min}$ at $72{ }^{\circ} \mathrm{C}$ for 30 cycles; and a final extension at $72{ }^{\circ} \mathrm{C}$ for $8 \mathrm{~min}$ (Figure 2). All PCR products were examined by electrophoresis (Bio-Rad Laboratories) on $2 \%$ agarose gels $(7 \mathrm{~cm} \times 10 \mathrm{~cm})$ in $1 \times$ Tris/borate/EDTA (TBE) buffer at $100 \mathrm{~V}$ for $30 \mathrm{~min}$ and observed using a Gel Documentation and Analysis system (Alpha Innotech). DNA 
A

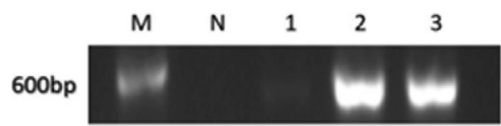

B

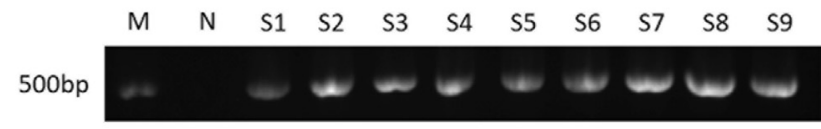

C

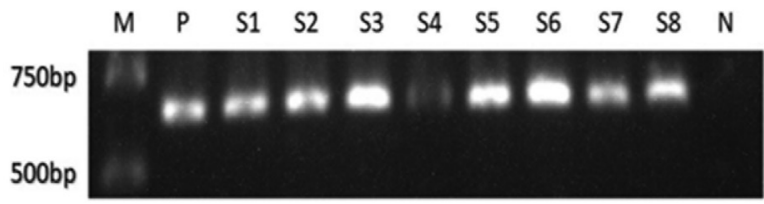

Figure 2. Expression of the variant of the gene for acrosomal binding protein, ACRBP-V5a and the gene for human glyceraldehyde 3-phosphate dehydrogenase (GAPDH) in tissues and cell lines. Left of the DNA ladder (lane M, catalog Nos. MD101-01 or MD104-01; Vazyme Biotech) are the respective numbers of base pairs. Lane $\mathrm{N}$, reaction mixture with $\mathrm{H}_{2} \mathrm{O}$ alone. (A) Primers located around the human ACRBP-V5a CDNA region are encoded by exons $4-5 \mathrm{a}$ and bands of 600 bp represent the splice variant. Lane 1 cDNA of SHG-44 (glioma cell line), lanes 2 and 3 hep G2 and 3 SMMC7721 (both hepatocarcinoma cell lines), respectively. (B) Lanes S1-9 represent tumor tissues of 9 patients and cloned 496 bp of GAPDH cDNA. (C) Positive control testis sample (lane P) derived from SMMC7721 CDNA.

markers (catalog Nos. MD101-01 and MD104-01) were from Vazyme Biotech Co.

\section{Quantitative real-time PCR}

Quantitative real-time PCR (qPCR) was run with 34 positive samples and the SMMC-7721 cell line (positive control) using a ChamQ Universal SYBR qPCR Master Mix (Vazyme Biotech) following the instructions provided by the manufacturer. Thermocycling conditions were as follows: $95{ }^{\circ} \mathrm{C}$ for $2 \mathrm{~min}$, followed by 40 cycles of $95^{\circ} \mathrm{C}$ for $10 \mathrm{~s}$, and $60{ }^{\circ} \mathrm{C}$ for $30 \mathrm{~s}$. Experiments were run in triplicate, and the average value of the quantification cycle $(\mathrm{Cq})$ was calculated for $A C R B P$ $V 5 a, A C R B P, G A P D H$ (reference gene), and the No Template Control (NTC), respectively. qPCR efficiency was about $90 \%-100 \%$. Linear dynamic range (LDR) was about $10^{3}-10^{10}$ DNA copies $/ \mathrm{mL}$, and $R^{2}$ was $>0.99$. The limit of detection (LOD) was $>10^{3}$. Details of primer sequences and amplicons are presented in Figures $\mathbf{1}$ and $\mathbf{4}$. The resulting relative increases in reporter SYBR Green I emission were analyzed using LightCycler 480 software (Roche).

\section{Statistical analyses}

The data were analyzed using IBM SPSS Statistics for Windows (version 20.0) and the results are described as percentages or mean $\pm \mathrm{SE}$ (standard error). A $\chi^{2}$ test was used to determine the differences in the number of mRNA positive samples and clinicopathological categories of sex, age, or Karnofsky Performance Status, and one-way analysis of variance (ANOVA) was used to determine any difference for the various tumor types. Student $t$ tests were used to determine differences in the levels of expression between the various clinicopathological categories and a Kruskal-Wallis test was used to determine differences between the various tumor types. A Mann-Whitney $U$ test was used to determine whether there was a significant association between the ratio of $A C R B P$ to $A C R B P-V 5 a$ for each sample and tumor type. $P<0.05$ was considered significant.

\section{Results}

\section{Identification and cloning of the novel splicing variant of human ACRBP retaining the intron}

A new splicing variant of $A C R B P$, named $A C R B P-V 5 a$, was cloned from the cDNA of human brain tumor specimens and liver cancer cell lines. Gel electrophoresis of RT-PCR products amplified using the newly designed primers according to the special fragment and cDNA from the cell line as template were used to identify $A C R B P-V 5 a$. Sequence analysis shows that $A C R B P-V 5 a$ originated from partial splice of intron 5 and ended the expression of the next 5 exons compared with the full-length cDNA. The predicted amino acid (AA) and $A C R B P-V 5 a$ and the full-length gene were compared (Figure 1).

\section{ACRBP-V5a expression in the 3 types of brain tumors}

To assess the presence of $A C R B P-V 5 a$ mRNA in the tumor tissue samples, RT-PCR was conducted and the transcription products were examined (Figure 2). We found 34/92 (37\%) of the tumor samples to be positive for $A C R B P-V 5 a$ mRNA, with 

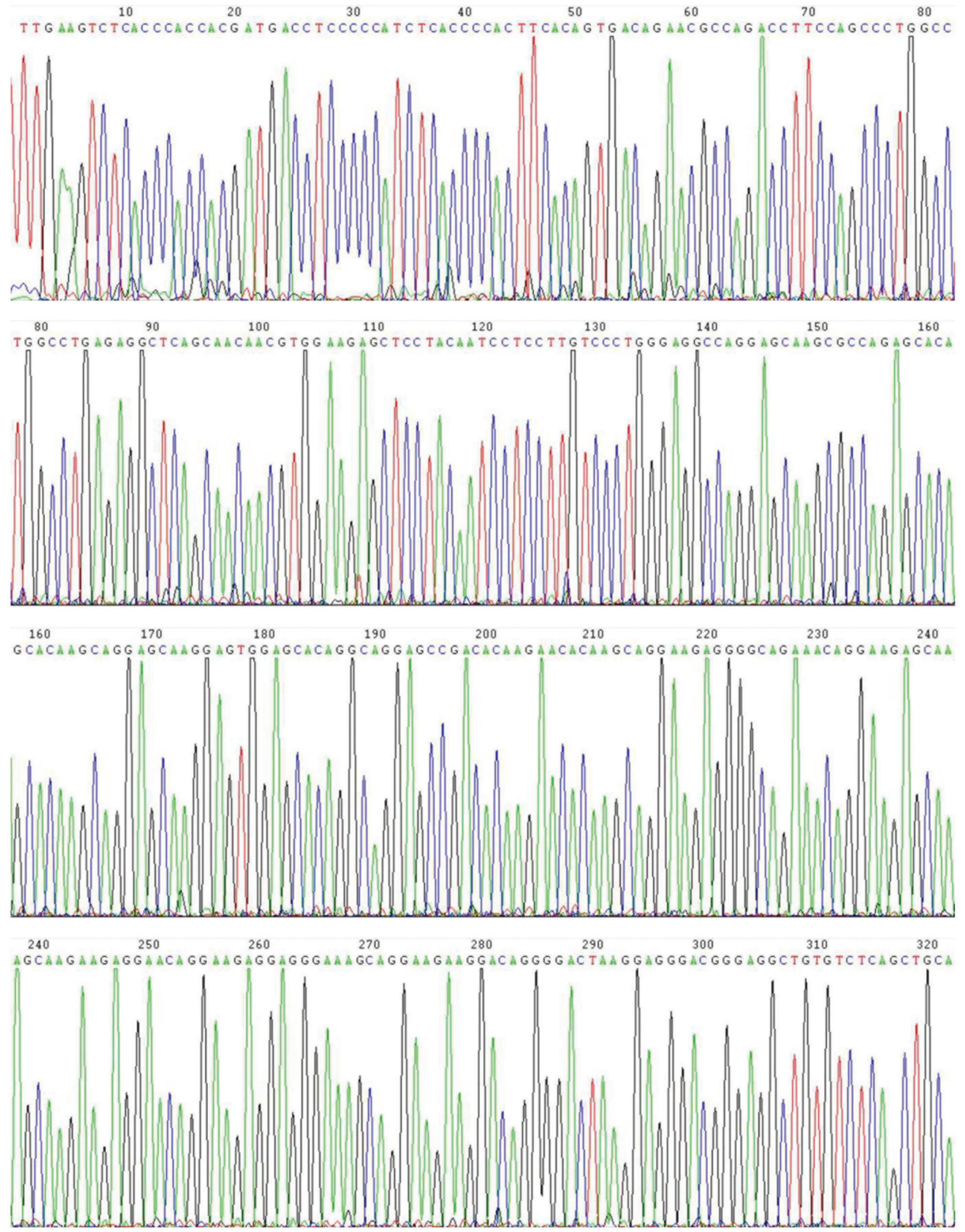

Figure 3. Continued 

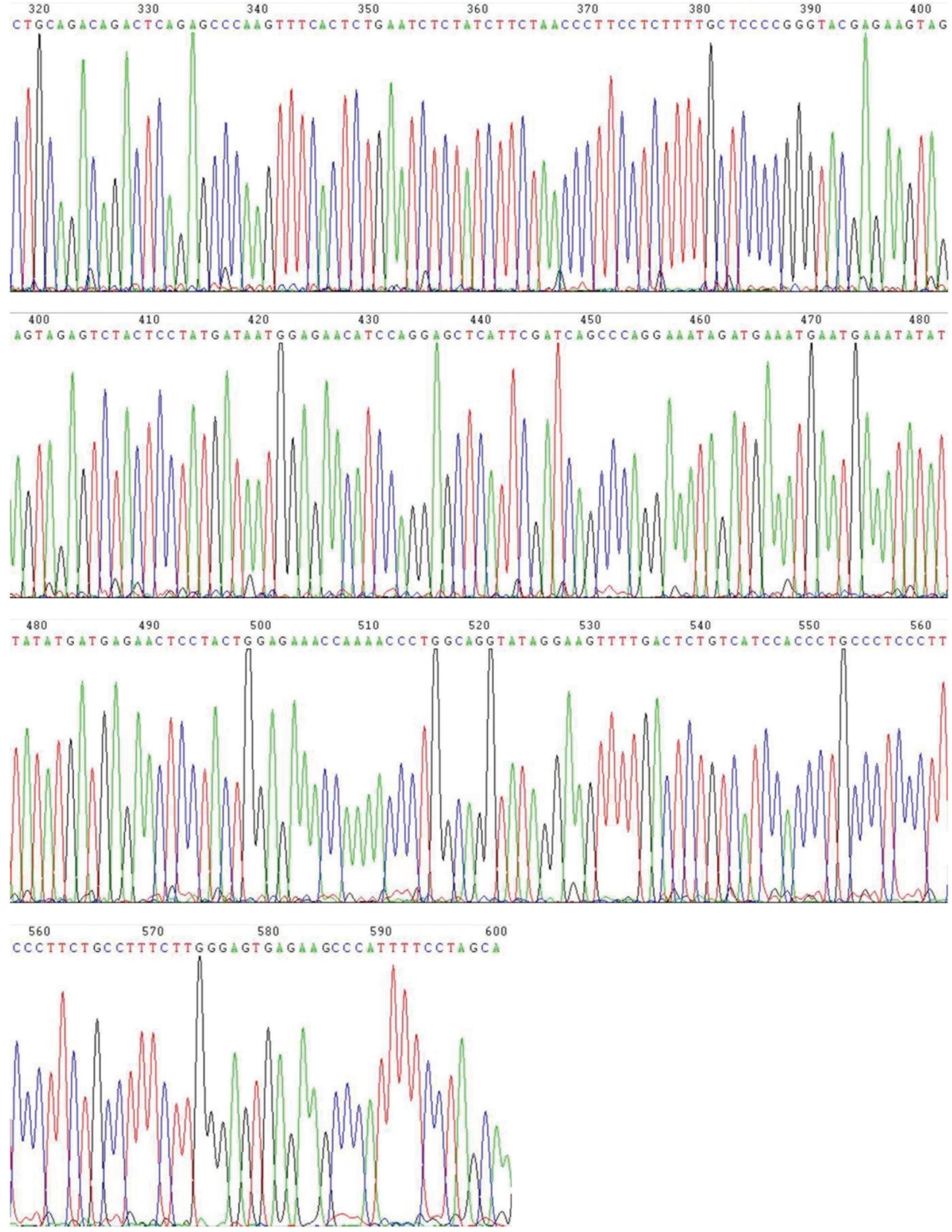

Figure 3. Sequence of the TA cloning result for the variant of the gene for acrosomal binding protein, $A C R B P-V 5 a$. 


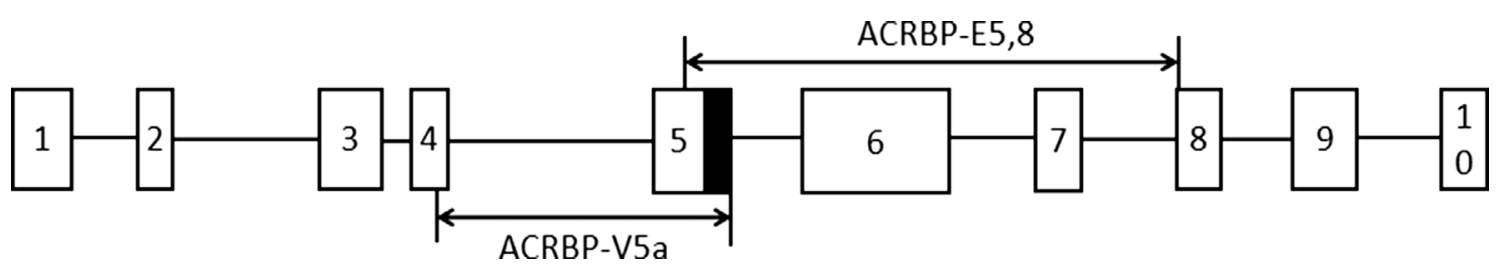

Figure 4. Genomic structure of the gene for acrosomal binding protein, ACRBP. The exons are shown as boxes and the introns as lines. The dark box is exon $5 \mathrm{a}$. Two double-headed arrows represent the cloning sequences of $\mathrm{E} 5$, E8, and V5a respectively.

Table 1. Analysis of ACRBP-V5a expression and clinicopathological characteristics

\begin{tabular}{|c|c|c|c|c|}
\hline $\begin{array}{l}\text { Clinicopathological } \\
\text { characteristic }\end{array}$ & $\begin{array}{c}\text { No. of mRNA } \\
\text { positive patient } \\
\text { samples/total } \\
\text { samples (\%) }\end{array}$ & $+P$ & $\begin{array}{c}\text { Relative } \\
\text { expression } \\
\text { Mean } \pm \text { SE }\end{array}$ & $\neq P$ \\
\hline \multicolumn{5}{|l|}{ Sex } \\
\hline Male & $21 / 63(33.3)$ & 0.29 & $46.7 \pm 14.0$ & 0.81 \\
\hline Female & $13 / 29(44.8)$ & & $41.7 \pm 11.3$ & \\
\hline \multicolumn{5}{|l|}{ Age (years) } \\
\hline$<34$ & $20 / 46(43.5)$ & 0.20 & $50.7 \pm 9.5$ & 0.47 \\
\hline$\geq 34$ & $14 / 46(30.4)$ & & $36.4 \pm 19.1$ & \\
\hline \multicolumn{5}{|l|}{ KPS§ } \\
\hline$<70$ & $15 / 34(44.1)$ & 0.28 & $57.6 \pm 18.7$ & 0.24 \\
\hline$\geq 70$ & $19 / 58(32.8)$ & & $34.7 \pm 8.5$ & \\
\hline \multicolumn{5}{|l|}{ Tumor gradell } \\
\hline ॥ & $10 / 33(30.3)$ & 0.32 & $17.7 \pm 3.8$ & $0.01^{*}$ \\
\hline IV & $24 / 59(40.7)$ & & $56.1 \pm 12.8$ & \\
\hline \multicolumn{5}{|l|}{ Tumor type } \\
\hline Astrocytoma & $10 / 33(30.3)$ & 0.309 & $17.7 \pm 3.8$ & $0.02^{*}$ \\
\hline Glioblastoma & $10 / 30(33.3)$ & & $50.4 \pm 26.1$ & \\
\hline Medulloblastoma & $14 / 29(48.3)$ & & $60.2 \pm 12.7$ & \\
\hline
\end{tabular}

$+x^{2}$ test and $\neq$ Student $t$ test, except for tumor type, which was calculated using a Kruskal-Wallis test.

§Karnofsky performance status.

|l World Health Organization (2016).

१One-way ANOVA.

${ }^{*} P<0.05$.

$10 / 33(30 \%)$ of astrocytoma, 10/30 (33\%) of glioblastoma, and 14/29 (48\%) of medulloblastoma samples positive for ACRBP-V 5 a mRNA. A one-way ANOVA found no significant differences in the proportions of positive samples between the 3 types of brain tumors (Table 1).

\section{Association between ACRBP-V5a and clinicopathological characteristics}

The association between $A C R B P-V 5 a$ mRNA transcription and the clinicopathological characteristics of patients, including categories of sex, age, Karnofsky performance status
(KPS), and WHO tumor grade, was determined using RT-PCR and $\mathrm{qPCR}$. The mean patient age was 33.5 years (range 2-78 years). All tumor tissues were classified according to World Health Organization (WHO) criteria [13], with 33 cases of WHO grade II and 59 cases of WHO grade IV identified. No significant differences were observed between expression of $A C R B P-V 5 a$ and clinicopathological characteristics except for the level of expression in tumor grade and tumor type (Table 1). It is noteworthy that a one-way ANOVA only indicated a significant difference between level of expression between astrocytomas and medulloblastomas $(P=0.017)$.

\section{Association between the ratio of ACRBP to ACRBP-V5a and the 3 types of brain tumors}

$A C R B P$ (exons 5-8) expression was examined in all the samples positive for $A C R B P-V 5 a$ (34 cases) by qPCR, and was present in all the samples. ACRBP-V5a expression was determined as described previously. The ratio of $A C R B P$ to $A C R B P-V 5 a$ was calculated for each sample and the ratio was classified by different tumors and analyzed using a MannWhitney $U$ test. We found significant differences in association between pairs for glioblastoma vs. medulloblastoma and astrocytoma vs. medulloblastoma, but not for astrocytoma vs. glioblastoma (Figure 5).

\section{Discussion}

To summarize, this experiment describes a novel splice variant $A C R B P-V 5 a$ that has not been previously studied in brain tumors, to our knowledge. The primers newly designed in the present study can specifically amplify $A C R B P-V 5 a$. All 3 types of malignant brain tumor samples and liver cancer cells studied can express $A C R B P-V 5 a$. We did not find a significant difference in the expression of ACRBP-V5a and in the clinicopathological characteristics of the patients or the proportion of samples positive for ACRBP-V5a expression between the 3 types of malignant brain tumor samples. However, in samples positive for $A C R B P-V 5 a$ expression, the relative levels of 


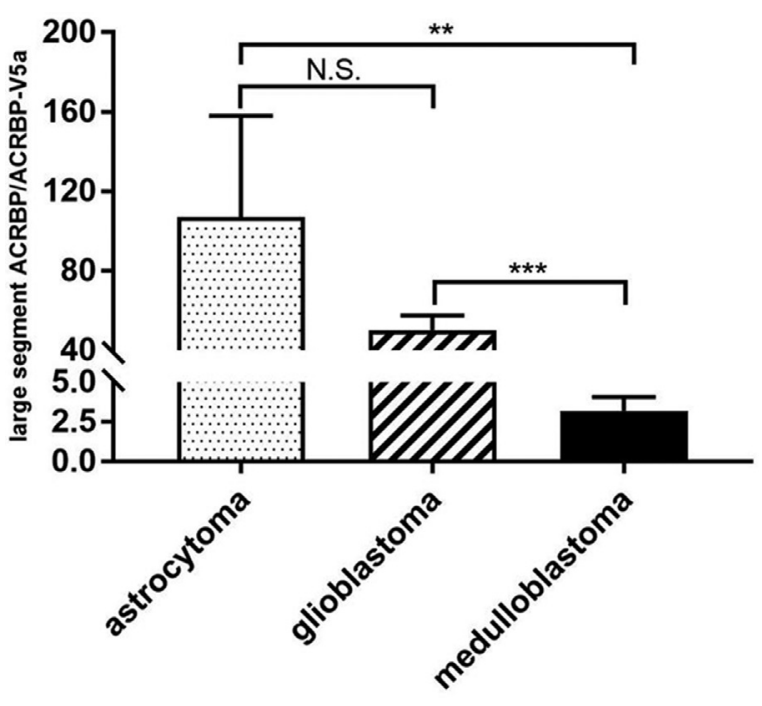

Figure 5. The ratios of $A C R B P$ to $A C R B P-V 5 a$ in the 3 types of brain tumors. Data represent mean $\pm \mathrm{SE}$. A Mann-Whitney $U$ test was used to determine the differences between the 3 different types. N.S.: not significant; ${ }^{* *} P<0.01,{ }^{* * *} P<0.001$.

expression were significantly different for tumor types and grades. The ratio $A C R B P / A C R B P-V 5 a$ was different between different tumor types, implying an association with different types of brain tumors.

A new database of sequencing analysis (GTEx) maintains 42,611 genes, of which 20,352 may potentially code protein and 22,259 may not, with 323,258 transcripts in total [14]. In general, every human gene translates 3 splicing variants; some of these will be regarded as nonsense-mediated mRNAs and be decomposed [15-17].

Alternative splicing confers genetic diversity in several ways, including competing $5^{\prime}$ splice sites, competing $3{ }^{\prime}$ splice sites, exon skipping, mutually exclusive exons, and intron retention [18]. For human $A C R B P$, there are 9 types of splicing variants predicted, 4 that are protein coding, 4 protein noncoding, and 1 that is nonsense. It is important to identify the specific function of other potential $A C R B P$ variants in the next stage of research.

Some variants of $A C R B P$ have been reported for mammals. Polakoski and Parrish [19, 20] detected a $29 \mathrm{kDa}$ protein in porcine sperm (similar to our $32 \mathrm{kDa}$ protein), which combined with proacrosin $(55 \mathrm{kDa})$ and a $49 \mathrm{kDa}$ intermediate. In 1989, these investigators demonstrated a $55-\mathrm{kDa}$ precursor protein of $A C R B P$ in porcine spermatogenic cells [2]. After posttranslational modification, a $32 \mathrm{kDa}$ mature form was produced by removing half of the $N$-terminal of the precursor during spermatogenesis. Baba et al. [2,3] asserted that both $A C R B P$ and proacrosin exist in the acrosomes of germ cells. However, they only identified the size of the $A C R B P$ protein and its function in procreation. We predicted the amino acid sequence of ACRBP-V5a and compared it with the porcine form (Figure 6). In general, the sequences are highly similar. Therefore, we propose that the $32 \mathrm{kDa}$ protein originates from $A C R B P-V 5 a$. In mice, unlike in other mammals, 2 different splicing isoforms are found for $A C R B P$ : a wild-type, $A C R B P-W$, and a variant, $A C R B P-V 5$. $A C R B P-V 5$ plays a role in the formation and configuration of the acrosome during early spermatogenesis [11]. We compared the structure of the human $A C R B P$ variant with $A C R B P$ $V 5$ of mice. We identified a distinctive characterization of the special splice variant of human $A C R B P$, which retained a part of intron 5 (exon 5a) and prevented the next translation; so, we named it $A C R B P-V 5 a$. Recently, we also identified and described ACRBP-V5a in liver and brain tumor cell lines. ACRBP is expressed in early embryonic development. In 2016, a medulloblastoma was removed from a glioma and divided into embryonic tumors as identified by the latest classification criteria [21]. Interestingly, even though we found no significant differences between the proportion of samples positive for ACRBP-V5a mRNA between the 3 types of brain tumors, the proportion of the positive medulloblastoma samples was higher than for glioblastomas or astrocytomas. This finding may provide evidence to support the latest classification for medulloblastoma [13]. It is also suggested that if the quantity of samples was increased, a significant difference may be found. Although no significant differences were found between the proportion of positive samples for age and tumor grade, an association should be suspected considering the high proportion and particularity of medulloblastoma [22].

The proportion of glioblastoma samples positive for ACRBP-V $5 a$ mRNA of $33 \%$ was higher than the $24 \%$ proportion predicted from the TCGA database (http://projects. insilico.us.com/TCGA Splice Seq/index.jsp). We may find a proportion closer to that predicted by increasing the number of samples. At the expression level, this implies that $A C R B P-V 5 a$ is associated with $A C R B P$. The level of expression of $A C R B P$ was higher than that for ACRBP-V5a. The ratio of $A C R B P$ expression to $A C R B P-V 5 a$ expression was significantly different between the 3 types of brain tumors. It was noteworthy that this phenomenon is not accidental or isolated. We found no such mechanism in the present study, but propose that the ratio $A C R B P / A C R B P-V 5 a$ is necessary to clarify potential links between various tumor types. The ratio may discriminate between different types of brain tumors.

Our study of alternative splicing of $A C R B P$ may provide a basis for the future research to investigate the function of $A C R B P-V 5 a$ and identify other potential splice variants of $A C R B P$ and their biological importance of the expression of the alternative splicing. 
Porcine MRQLAAGSLLSLLKVLLLPLAPAPAQDANSASTPGSPLSPTEYERFFALLTPTWKAETTC 60 Human MRKPAAGFLPSLLKVLLLPLAPAAAQDSTQASTPGSPLSPTEYERFFALLTPTWKAETTC $* *: * * * * * * * * * * * * * * * * * * * *: . * * * * * * * * * * * * * * * * * * * * * * * * * * * * * *$

Porcine VRCSQPVSILSPNSLKEVDTSSEVPITTMTSPVSSHITATGRQVFQPWPERLNNNVEELL VLCSQPVSILSPNTLKEIEASAEVSPTTMTSPISPHFTVTERQTFQPWPERLSNNVEELL $* * * * * * * * * * *: * * *:: ; * ; * * * * * * * *: * *: *, * * *, * * * * * * * *, * * * * * * *$

$\begin{array}{lll}\text { Porcine } & \text { QAG } & 539 \\ \text { Human } & -- & 319\end{array}$

Figure 6. Comparison of porcine (full-length) and human (V5a) amino acid sequences for acrosomal binding protein (ACRBP; Clustal Omega alignment program, https://www.ebi.ac.uk/Tools/msa/clustalo/). An * (asterisk) indicates positions that have a single, fully conserved residue. A: (colon) indicates conservation between groups (porcine and human) of strongly similar properties. A. (period) indicates conservation between groups of weakly similar properties.

Author contributions: The author contributed substantially to the conception and design of the study, collection of data, and its analysis and interpretation. The author contributed substantially to drafting and critical revision of the manuscript, approved the final version submitted for publication, and takes responsibility for statements made in the published article.

Acknowledgments: The author thanks Professor Xiaoxun Xie, Department of Histology and Embryology, and Guangxi Colleges and Universities Key Laboratory of Preclinical Medicine Research, Guangxi Medical University, Nanning,
Guangxi 530021, China, for contributions to drafting and critical revision of the manuscript, and Professor Shaowen Xiao, Department of Neurosurgery, The First Affiliated Hospital of Guangxi Medical University, Nanning, Guangxi 530021, China, for contributions to the conception and design of the study, funding acquisition and supervision of the project, collection of data, and its analysis and interpretation. The author thanks Ms. Fang Chen for technical assistance. The authors did not receive any specific grant for this research from any funding agency in the public, commercial, or not-for-profit sectors. The present address for Dr. Baolong Zheng is Clinic 
for Neurosurgery, University Hospital Düsseldorf, Düsseldorf 40225, Germany.

Conflicts of interest statement: The author has completed and submitted an International Committee of Medical Journal Editors Uniform Disclosure form for Potential Conflicts of Interest. Baolong Zheng has no potential or actual conflict of interest to disclose in relation to the published article.

Data sharing statement: The data sets generated and analyzed during the present study are included in the published article. The data generated or analyzed during the present study are available in the National Center for Biotechnology Information ClinVar repository, with accession number: SCV001441593, and will be shared by the authors upon reasonable request after deidentification of data from any individual patient.

\section{References}

[1] Ono T, Kurashige T, Harada N, Noguchi Y, Saika T, Niikawa N, et al. Identification of proacrosin binding protein sp32 precursor as a human cancer/testis antigen. Proc Natl Acad Sci U S A. 2001; 98:3282-7.

[2] Baba T, Michikawa Y, Kashiwabara S, Arai Y. Proacrosin activation in the presence of a 32-kDa protein from boar spermatozoa. Biochem Biophys Res Commun. 1989; 160:1026-32.

[3] Baba T, Niida Y, Michikawa Y, Kashiwabara S, Kodaira K, Takenaka $\mathrm{M}$, et al. An acrosomal protein, sp32, in mammalian sperm is a binding protein specific for two proacrosins and an acrosin intermediate. J Biol Chem. 1994; 269:10133-40.

[4] Wilkinson MF, Kleeman J, Richards J, MacLeod CL. A novel oncofetal gene is expressed in a stage-specific manner in murine embryonic development. Dev Biol. 1990; 141:451-5.

[5] Ono T, Sato S, Kimura N, Tanaka M, Shibuya A, Old LJ, Nakayama E. Serological analysis of BALB/C methylcholanthrene sarcoma Meth A by SEREX: identification of a cancer/testis antigen. Int J Cancer. 2000; 88:845-51.

[6] Li X, Yan J, Fan R, Luo B, Zhang Q, Lin Y, et al. Serum immunoreactivity of cancer/testis antigen OY TES-1 and its tissues expression in glioma. Oncol Lett. 2017; 13:3080-6.

[7] Fu X-D, Ares M, Jr. Context-dependent control of alternative splicing by RNA binding proteins. Nat Rev Genet. 2014; 15:689-701.

[8] Lander ES, Linton LM, Birren B, Nusbaum C, Zody MC, Baldwin J, et al. Initial sequencing and analysis of the human genome. Nature. 2001; 409(6822):860-921.
[9] Andreadis A. Tau gene alternative splicing: expression patterns, regulation and modulation of function in normal brain and neurodegenerative diseases. Biochim Biophys Acta. 2005; 1739:91-103

[10] Dvinge H, Kim E, Abdel-Wahab O, Bradley RK. RNA splicing factors as oncoproteins and tumour suppressors. Nat Rev Cancer. 2016; 16:413-30.

[11] Kanemori Y, Koga Y, Sudo M, Kang W, Kashiwabara S-I, Ikawa M, et al. Biogenesis of sperm acrosome is regulated by pre-mRNA alternative splicing of Acrbp in the mouse. Proc Natl Acad Sci U S A. 2016; 113:E3696-705.

[12] Black MW, Tuan A, Jonasson E. Cloning yeast actin cDNA leads to an investigative approach for the molecular biology laboratory. Biochem Mol Biol Educ. 2008; 36:217-24.

[13] Louis DN, Perry A, Reifenberger G, von Deimling A, FigarellaBranger D, Cavenee WK, et al. The 2016 World Health Organization Classification of Tumors of the Central Nervous System: a summary. Acta Neuropathologica. 2016; 131:803-20.

[14] Pertea M, Shumate A, Pertea G, Varabyou A, Breitwieser FP, Chang Y-C. CHESS: a new human gene catalog curated from thousands of large-scale RNA sequencing experiments reveals extensive transcriptional noise. Genome Biol. 2018; 19:208. doi: 10.1186/ s13059-018-1590-2

[15] Ast G. How did alternative splicing evolve? Nat Rev Genet. 2004; 5:773-82.

[16] Lovejoy CA, Li W, Reisenweber S, Thongthip S, Bruno J, de Lange T, et al. Loss of ATRX, genome instability, and an altered DNA damage response are hallmarks of the alternative lengthening of telomeres pathway. PLoS Genet. 2012; 8:e1002772. doi: 10.1371/journal. pgen. 1002772

[17] Baek D, Green P. Sequence conservation, relative isoform frequencies, and nonsense-mediated decay in evolutionarily conserved alternative splicing. Proc Natl Acad Sci U S A. 2005; 102:12813-8.

[18] Grasso C, Modrek B, Xing Y, Lee C. Genome-wide detection of alternative splicing in expressed sequences using partial order multiple sequence alignment graphs. Pac Symp Biocomp. 2004; 9:29-41.

[19] Polakoski KL, Parrish RF. Boar proacrosin. Purification and preliminary activation studies of proacrosin isolated from ejaculated boar sperm. J Biol Chem. 1977; 252:1888-94.

[20] Parrish RF, Polakoski KL. An apparent high molecular weight form of boar proacrosin resulting from the presence of a protein that binds to proacrosin. Anal Biochem. 1978; 87:108-13.

[21] Louis DN, Aldape K, Brat DJ, Capper D, Ellison DW, Hawkins C, et al. Announcing cIMPACT-NOW: The Consortium to Inform Molecular and Practical Approaches to CNS Tumor Taxonomy. Acta Neuropathologica. 2017; 133:1-3.

[22] Cavalli FMG, Remke M, Rampasek L, Peacock J, Shih DJH, Luu B, et al. Intertumoral heterogeneity within medulloblastoma subgroups. Cancer Cell. 2017; 31:737-54.e6. doi: 10.1016/j. ccell.2017.05.005 